\title{
UM OLHAR SOBRE A EDUCAÇÃO NO CAMPO: o projeto político pedagógico da escola estadual professor João Florentino da Silva Neto, na cidade de Cáceres-MT.
}

\author{
Leandro de Almeida \\ Joana Paulin Romanowski
}

Resumo

Este estudo teve como objetivo analisar os reflexos e contribuições do Projeto Político Pedagógico na educação do campo, analisando em que medida tem ajudado a reforçar a identidade dos seus educandos enquanto sujeitos do campo. Trata-se de uma pesquisa bibliográfica que, no contexto da Educação do Campo, foi realizada com uma pequena abordagem acerca da classe multisseriada e a construção de Identidades. Nesse sentido, tratou-se do Projeto Político Pedagógico a partir do entendimento teórico das Diretrizes Operacionais da Educação Básica do Campo - DOEBC, a qual aponta a necessidade da valorização da identidade camponesa, cultural e trabalhadora dos alunos do campo por meio de Projetos Políticos Pedagógicos com conteúdos curriculares e metodologias adequadas às reais necessidades desses alunos. Para tal, foi traçada uma leitura do documento oficial da Escola Estadual Professor Joao Florentino da Silva Neto, na cidade de Cáceres-MT, como parâmetro afirmativo de uma proposta de educação do Campo.

Palavras-chave: educação do campo; projeto político pedagógico; classe multisseriada.

A LOOK AT EDUCATION IN THE FIELD: the political pedagogical project of the state school professor João Florentino da Silva Neto, in the city of Cáceres-MT.

Abstract

This study aimed to analyze the reflexes and contributions of the Pedagogical Political Project in rural education, analyzing to what extent it has helped to reinforce the identity of its students as subjects in the rural area. It is a bibliographic research that, in the context of Rural Education, a small approach was made about the multiseriate class and the construction of Identities. In this sense, it was the Pedagogical Political Project based on the theoretical understanding of the Operational Guidelines for Basic Education in the Field - DOEBC, which points out the need to enhance the rural, cultural and worker identity of students in the field through Pedagogical Political Projects with curricular contents and methodologies appropriate to the real needs of these students. To this end, a reading of the PPP of the State School Professor Joao Florentino da Silva Neto was traced, in the city of Cáceres-MT, as an affirmative parameter of a proposal for rural education.

Keywords: rural education; pedagogical political project; multi-grade class. 
DOI: $10.12957 /$ teias.2021.59095

\section{UNA MIRADA A LA EDUCACIÓN EN EL CAMPO: \\ el proyecto político pedagógico del profesor de escuela estatal João Florentino da Silva Neto, en la ciudad de Cáceres-MT.}

Resumen

Este estudio tuvo como objetivo analizar los reflejos y aportes del Proyecto Político Pedagógico en la educación rural, analizando en qué medida ha contribuido a reforzar la identidad de sus estudiantes como sujetos del ámbito rural. Se trata de una investigación bibliográfica que, en el contexto de la Educación Rural, se realizó una pequeña aproximación sobre la clase multiseriada y la construcción de Identidades. En este sentido, fue el Proyecto Político Pedagógico basado en la comprensión teórica de los Lineamientos Operativos para la Educación Básica en el Campo - DOEBC, que señala la necesidad de potenciar la identidad rural, cultural y trabajadora de los estudiantes rurales a través de Proyectos Políticos Pedagógicos con Contenidos y metodologías curriculares adecuados a las necesidades reales de estos estudiantes. Para ello, se trazó una lectura del PPP del profesor de la Escuela Estatal Joao Florentino da Silva Neto, en la ciudad de Cáceres-MT, como parámetro afirmativo de una propuesta de educación rural.

Palabras clave: educación rural; proyecto político pedagógico; clase de vários grados.

\section{INTRODUÇÃO}

Este artigo tem por objetivos mostrar os reflexos e as contribuições de um Projeto Político Pedagógico (doravante PPP) para o cotidiano da educação do/no campo, para tanto, apresenta-se a experiência da Escola Estadual Professor João Florentino da Silva Neto, na cidade de Cáceres, Mato Grosso e, de acordo com o que se pretende diagnosticar, analisar em que medida o PPP desta escola tem ajudado a reforçar a identidade dos educandos enquanto sujeitos do campo, bem como, a vinculação desse documento com a concepção de Educação do/no Campo. Como tal, buscouse discutir inicialmente a questão teórica na área a partir das terminologias - Educação do Campo no Brasil; as classes multisseriadas; e, a construção de identidades.

No que se refere ao Projeto Político Pedagógico (PPP), o presente trabalho se constituiu por meio das abordagens propostas nas Diretrizes Operacionais da Educação Básica do Campo DOEBC que tem se mostrado uma ferramenta importante da valorização da identidade camponesa, cultural e trabalhadora dos alunos do campo por meio do planejamento dos PPPs, contemplando conteúdos curriculares e metodologias adequadas às reais necessidades dos alunos que se aproximam cada vez mais à prática do discurso político cidadão voltado para a Educação do/no campo.

Adiante, os achados da pesquisa bibliográfica evidenciam que é essencial a existência de um PPP vinculado aos princípios de Educação do Campo e por meio deste documento resgatar o sentimento de valorização dos educandos para autoafirmá-los como sujeitos transformadores, dentro do grupo social em que estão inseridos, sem o sentimento de inferioridade que minimiza o saber e ignora a importância dos afazeres tradicionais de uma comunidade. Em síntese, por tudo que está sinalizado nesse artigo, ousa-se dizer que o Projeto Político Pedagógico só tem sentido se estiver colado às lutas sociais, ao trabalho coletivo, à perspectiva da classe trabalhadora e à construção de um projeto inserido no contexto da educação do/no campo e seu entorno. 
DOI: $10.12957 /$ teias.2021.59095

\section{EDUCAÇÃO DO CAMPO E OS MOVIMENTOS SOCIAIS NA LUTA PELA TERRA NO BRASIL}

O fim da Era Vargas (1945) trouxe a redemocratização e consigo as lutas sociais ganharam forças, incluindo os movimentos voltados para o campo. No Nordeste, as Ligas Camponesas encamparam a consolidação dos movimentos sociais populares e, sobretudo, nos meados de 1950 surgiram as mobilizações em torno de melhores condições para os trabalhadores da cidade e do campo que adquiriram visibilidade, em decorrência das manifestações em espaços públicos (praças, rodovias, universidades etc.). Assim, o povo do campo recebeu o apoio das Comunidades Eclesiais de Base - CEBs, estas ligadas à igreja católica, instituição que organizava o povo para a reivindicação dos direitos populares a fim de garantir a forte participação de leigos no movimento. Muito importante o papel das CEBs na luta pela reforma agrária e em favor das ocupações dos latifúndios, dentre outras lutas sociais voltadas para a criação de políticas públicas em favor do campesinato (BOFF, 2008).

Além das CEBs, a Comissão Pastoral da Terra (CPT) também encampou as muitas lutas elencadas pelo campesinato, sendo o campo brasileiro caracterizado pelos diversos conflitos, essenciais e radicalmente fruto da frágil e precária Política Pública efetiva de Reforma Agrária. Esse fato constitui-se até hoje o contraponto da questão agrária brasileira. É nesse contexto que comparecem os movimentos sociais de luta pela terra e pela Reforma Agrária, que se processam forçosos acampamentos de terras devolutas e improdutivas de particulares, sendo que muitos proprietários nem são seus donos legítimos, sendo as áreas ocupadas denominadas de latifúndios.

O Movimento dos Trabalhadores Rurais Sem Terra (MST) é fruto das lutas pela democratização da terra e da sociedade. No final da década de 1970, quando as contradições do modelo agrícola se tornou mais intenso e sofreu com a violência de Estado, dado a ausência de políticas públicas para o campo. Desta maneira, ressurgem as ocupações de terra, embora a Reforma Agrária seja o objetivo central do movimento camponês, no contexto político e econômico que obrigou o MST a construir alianças junto às organizações internas estas voltadas para outros núcleos e setores do movimento, centralizados na educação, na cultura e na politização dos militantes. Entre os desafios da luta camponesa, coloca-se em pauta a necessidade de desenvolver a solidariedade entre a sociedade e a introdução de novos valores culturais por meio de uma unidade entre o campo e a cidade (BARROS, 2007).

O MST é, segundo Amin e Houtart (2003), caracterizado por lutas de massa e por exercer uma grande pressão social e política, sem tornar-se um partido político, mas com uma dimensão sociopolítica de peso. Se a finalidade básica desse Movimento é a obtenção de terras, isso se justifica em respeito a um postulado de igualdade perante o acesso a terra, qualquer pessoa tem o direito de suprir suas necessidades de maneira autônoma - essa reivindicação inscreve-se num projeto de sociedade amplo, igualitário, solidário, democrático, ecológico, que o MST procura construir na sua prática cotidiana, dentro dos assentamentos através de implantações coletivas de acampamento.

Para Munarin (2006), as constantes lutas dos movimentos sociais no Brasil reforçam o enfoque voltado às concepções marxistas, seja pelas lutas travadas socialmente pelos direitos, seja pelo aspecto coletivo que existe na sua organização, esteja esta vinculada ao espaço urbano e/ou ao campo. Nesse sentido, é possível perceber que a Educação do Campo nasce baseada em uma concepção educacional popular, de natureza socializadora que atenta contra aos ideais capitalistas da época. Atentamos ainda para uma pertinência para a busca por melhores condições, sobretudo pelo campesinato que, "[...] de maneira geral [...], é formado a partir da população empobrecida, que cresceu à margem das desigualdades sociais, através de uma divisão agrária injusta, que 
estigmatizou essa camada da população" (CARMONA et al., 2019, p. 543).

Por esse entendimento, os múltiplos Movimentos que sugiram antes da Ditadura Militar (1964-1985) foram sufocados na sua essência, dando lugar a uma educação tecnicista, na contramão do que pensava o educador Paulo Freire (1981), que idealizada uma educação libertadora, voltada para a formação da consciência crítica na qual educadores e educandos entrelaçam saberes e atuam em prol da mancipação popular. Portanto, o pensamento pedagógico de Freire voltou-se para educar jovens e adultos, sobretudo, na luta pela educação do/no campo.

\section{ALGUNS MOMENTOS HISTÓRICO DA EDUCAÇÃO DO CAMPO NO BRASIL: CONCEITOS, PRINCÍPIOS E DIRETRIZES}

O conceito de Educação do Campo se originou no cenário brasileiro no início do século $\mathrm{XX}$, com o crescente número de camponeses que saíam do campo em busca de empregos na cidade. Em decorrência desse fato o governo brasileiro desenvolveu uma educação para atender não apenas a demanda industrial, em grande expansão na época, criando com isto uma concepção do rural como o lugar de atraso e do urbano como um lugar de progresso, atraindo, de forma até obvia, as populações campesinas para os centros urbanos, principalmente aquelas que fugiam de terras áridas do Nordeste, por exemplo, de latifundiários, que empregavam, quase sempre a violência, como forma de controlar essa população explorando-a de maneira indiscriminada (CARMONA; LUNA, 2019).

Assim, ao longo da história da educação brasileira o campo foi tratado como secundário, o quê pode ser percebido na trajetória histórico-política da sociedade brasileira, nascida de uma elite agrária que negou a essa população o acesso aos avanços ocorridos nas duas últimas décadas como o reconhecimento e a garantia do direito à educação básica. Arroyo, Caldart e Molina (2004) reforçam essa ideia quando compartilham da seguinte opinião: a escola, no meio rural, foi tratada como resíduo do sistema educacional brasileiro, para qual os investimentos foram escassos ou inexistentes.

Em meados dos anos de 1950, iniciou-se no Brasil um processo de dualismo na qual as economias começam a trilhar caminhos distintos, os caminhos percorridos pela indústria e pela agricultura. E é justamente no contexto dessa dicotomia indústria/agricultura que surgiram termos antagônicos como bem afirma Sandroni (1999) ou um setor moderno e o outro "arcaico", um "avançado" e outro "atrasado" ou um é rural e outro é urbano. Nessa perspectiva, a partir do desenvolvimento das indústrias os governantes passaram a ter essa visão dualista, uma para o setor rural, de relativo abandono, e outra para as cidades em via de industrialização, de apoio e preocupação, ou seja, não há a preocupação em educar uma mão de obra, vista como força braçal, ligada à terra (CARMONA, LUNA, 2019).

Ainda no governo militar, os gestores praticamente mantiveram a mesma concepção e, no final deste governo, sem avanços sociais, políticos e econômicos para o campo, os trabalhadores rurais começaram a se mobilizar frente às políticas governamentais de construção de usinas hidroelétricas, da concentração de terras nas mãos de latifundiários, dos projetos de colonização da Amazônia, dentre os mais organizados, destaca-se o Movimento dos Trabalhadores Rurais Sem Terra (MST). Salientamos o apoio da igreja e o papel da Teologia da Libertação que exerceram sensível influência aos movimentos populares na América Latina, sobretudo no Brasil.

A consolidação do MST ocorreu, em 1984, em decorrência da preocupação com a educação das crianças assentadas, pensando na garantia de uma educação voltada à realidade do assentamento. A partir dessa preocupação, iniciam-se as primeiras discussões a respeito de uma 
Educação do Campo, que:

Nasceu como mobilização/pressão de movimentos sociais por uma política educacional para comunidades camponesas: nasceu da combinação das lutas dos sem-terra pela implantação de escolas públicas nas áreas de reformas agrária com as lutas e resistências de inúmeras organizações e comunidades camponesas para não perder suas escolas, suas experiências de educação, suas comunidades, seus territórios, sua identidade (CALDART, 2008, p. 71).

Nesse contexto, Leite (1999), Arroyo, Caldart e Molina (2004) asseguram que no final do século XX o Brasil assistiu a instigante presença dos sujeitos do campo no cenário político e cultural do país, como também a inserção destes nos movimentos sociais do campo. Tais sujeitos se mostraram diferente, exigindo respeito. Denunciaram, nesse ínterim, o silenciamento e o esquecimento por parte dos órgãos governamentais, lutando por uma escola do/no campo que não fosse apenas uma extensão da escola urbana e, sim, uma escola atenta aos seus sujeitos específicos.

Nesse sentido, o MST atuou e participou permanentemente na construção do seu projeto pedagógico, destacando a Educação Popular. Nesse contexto nacional, a Educação Popular surgiu, a partir dos anos de 1950, através das práticas de Educação de Jovens e Adultos, intitulada Educação de Base, iniciado através das experiências de Paulo Freire e de sua Educação Libertadora do sujeito oprimido (FREIRE, 2011; 1981). Pelo exposto, historicamente, a educação brasileira tem privilegiado a formação da elite. Por isso, o tratamento da Educação do Campo é reivindicado pelos movimentos sociais como público de direito, respeitando a população do campo.

A Educação do Campo, ao longo dos anos vem sendo esquecida pelo poder público, é uma das dimensões da diversidade sociocultural de nosso país que não pode mais ser negada. Os programas emergenciais e as políticas compensatórias de outrora, pensadas por agentes externos, centradas no aspecto econômico-produtivo e referenciadas em um padrão de cultura urbana, retratam a perspectiva de tratamento utilitarista e discriminatório dado ao campo (MACHADO e VENDRAMINI, 2013).

Para Arroyo (2011), os Estados e municípios ainda insistem em tratar como Educação Rural, por isso é necessária uma redefinição profunda, ou seja, uma Política de Educação do Campo. Então, quer seja NO e DO campo, as políticas públicas são necessárias no sentido de assegurar o acesso universal à educação. Segundo Caldart (2005, p. 25-26): NO significa que o "[...] povo tem direito a ser educado no lugar onde vive; DO: o povo tem direito a uma participação pensada desde o seu lugar e com a sua participação, vinculada à sua cultura e às suas necessidades humanas e sociais".

\section{EDUCAÇÃO DO CAMPO E SUA RELAÇÃO COM A EDUCAÇÃO POPULAR}

Novamente apresentamos algumas ações do MST, por ser este movimento o que melhor e, mais seriamente fomenta o processo de Educação do/no Campo, estruturando a base conceitual desta educação. Norteada, entre os muitos educadores populares, o projeto de Paulo Freire e de sua educação libertadora do sujeito oprimido tem deixado profundas contribuições teóricas para a Educação do/no Campo. Compreende-se a Educação Popular como uma concepção de educação baseada na pedagogia libertadora, visando a superação da condição de oprimido, possui a intencionalidade de transformar a realidade de vida a partir do protagonismo dos sujeitos (FREIRE, 1981).

O termo popular se define de acordo com o dicionário brasileiro como sendo algo do povo, 
para o povo, que atende às necessidades do povo. $\mathrm{Na}$ concepção Freiriana o termo popular se conceitua oprimido, aquele que vive sem condições elementares para o exercício de sua cidadania, excluído da posse e do uso dos bens materiais produzidos pelo sistema econômico atual.

Como se observa, a Educação Popular se constitui das lutas concretas, em busca de transformação das classes de exclusão, opressão e carências que caracterizam o cotidiano dos povos oprimidos. Na concepção de Brandão (1986) o que leva a marginalização dos oprimidos, das classes subalternas da sociedade desigual é a grande separação entre o conhecimento erudito e o popular. Pois, segundo o autor:

Um saber da comunidade torna-se o saber das frações (classes, grupos, povos, tribos) subalternas da sociedade desigual. Em um primeiro longínquo sentido, as formas - imersas ou não em outras práticas sociais, através das quais o saber das classes populares ou das comunidades sem classes é transferido entre grupos ou pessoas, são a sua educação popular (BRANDÃO, 1986, p. 26).

Nesse lugar, Brandão (1986) considera que surge a Educação popular, podendo ser definida como uma teoria de conhecimento pautada na realidade, com metodologias incentivadoras à participação, intercalada por uma base política estimuladora de transformações sociais e orientada pela busca humana de liberdade, justiça, igualdade e felicidade. Nessa mesma linha de raciocínio Freire $(2011 ; 1992 ; 1981)$ enfatiza que somente se libertando, os oprimidos podem libertar os opressores:

O oprimido, libertando-se, liberta o opressor, o não haver, como antes sublinhei, declarado que a luta de classes é o motor da história, o reatamento que eu dava ao indivíduo, sem aceitar reduzi-lo a puro reflexo das estruturas socioeconômicas, o tratamento que dava à consciência, à importância da subjetividade, o papel da conscientização que, na Pedagogia do oprimido, supera, em termos de criticidade, o a ela atribuído em Educação como prática da liberdade (FREIRE, 1992, p. 90).

O que se pode observar é, que nesse pressuposto de uma educação libertadora, somente a classe subalterna pode conduzir esse processo de libertação e construir essa nova sociedade, pois a classe dominante não poderá conduzir a essa transformação. Nessa expectativa, a Educação do Campo mantém uma estreita relação com a Educação Popular, tendo em vista que, a Educação do Campo se fundamenta nas ideias do educador Paulo Freire, tendo como princípios filosóficos, políticos, sociológicos, culturais uma identidade popular, principalmente quando pensamos a educação no sentido contemporâneo.

A Educação do Campo refletida a partir dos próprios camponeses simboliza uma proposta contra-hegemônica das classes trabalhadoras que respeitando a diversidade cultural que lhes caracteriza, assume novo caminho, construído essencialmente no interior dos próprios movimentos sociais na disputa da formação dos sujeitos do campo. Desse modo, esse paradigma de educação, que os movimentos sociais populares do campo têm reivindicado e discutido para a população do campo, contém a teoria freiriana manifestada na Educação Popular por intermédio do compromisso com uma prática educativa libertadora.

Porém, a ligação dos momentos históricos com a educação e os aspectos legais, intensificam o pensamento de que as mudanças, em nenhum momento, mostraram-se primordialmente em favor da formação cidadão das classes populares, sempre foi à lógica do mercado que motivou tais mudanças e os trabalhadores estavam no meio como mais um elemento para o sucesso dos empreendimentos capitalistas. Portanto, a Educação do Campo apresenta na sua história um 
caminho percorrido de lutas, reivindicações e, principalmente, participação coletiva dos movimentos sociais. Esse entendimento leva a perceber que a atuação para a modalidade do campo não pode desvincular-se desses princípios. Compreende-la como direito dos povos do campo inspira-nos a tarefa de comprometermo-nos também nesse sentido.

\section{CONSIDERAÇÕES ACERCA DAS CLASSES MULTISSERIADAS}

As escolas multisseriadas foram organizadas em uma única sala, na qual reúnem-se os alunos pertencentes a várias séries e sob a regência de um único professor. Esta tem sido a realidade muito comum nos espaços das escolas do campo brasileira. Esse tipo de escola destina-se tanto à população periférica quanto à rural, porém, hoje se concentram na zona rural, notadamente no Norte e Nordeste. Ao instituir o verbete Escolas Multisseriadas, no Dicionário Interativo da Educação Brasileira, definiram e afirmaram que:

As classes multisseriadas existem principalmente nas escolas do meio rural, visando diminuir a evasão escolar, ou em projetos específicos, baseados na metodologia da aceleração e no telecurso, buscando atrair crianças e adolescentes em situação de rua, analfabetas ou defasadas em seus estudos, para que possam aprender e serem convencidos a continuar na vida escolar (MENEZES E SANTOS, 2002, p. 2).

Geralmente, nessas turmas, são destinados para lecionar professores que são considerados "inaptos" para atuar nas turmas das escolas da zona urbana ou, muitas vezes, por "vingança" e perseguição "política", o que se torna um problema, pois causa fragilidade no comprometimento com as classes multiseriadas, os alunos e a comunidade como um todo (ANTUNES-ROCHA; HAGE, 2010).

Na maioria das vezes, esses professores não têm uma formação política e pedagógica para lidar com realidade do multisseriamento. Uma realidade que ainda se agrava pela ausência ou pela "timidez" das políticas públicas destinadas para este contexto. Assim:

As escolas multisseriadas são, historicamente, consideradas como de segunda categoria e, o que é pior, sem alternativa de melhoria; por isso, os educadores e os gestores optaram por esquecê-las, esperando que desapareçam como consequência natural do processo de desenvolvimento das sociedades. Porém, o desaparecimento natural de qualquer instituição não existe na história. A sua permanência ou desaparecimento depende de sua função social, se necessária ou já desnecessária em determinado momento da sociedade. Por essa razão, apesar de todas as mazelas e das políticas de substituição promulgadas desde a década de 1980, as escolas multisseriadas vêm resistindo e adentraram o século XXI (PIZA; SENA, 2001, p.13).

As classes multisseriadas representam uma luta política e pedagógica relevante para as populações que atendem, na medida em que "as escolas multisseriadas, em que pesem todas as mazelas explicitadas, têm assumido a responsabilidade quanto à iniciação escolar da grande maioria dos sujeitos no campo" (HAGE, 2006 p. 4).

Portanto, estas escolas, ainda hoje, são as responsáveis pela iniciação escolar de grandes contingentes de brasileiros. A ausência delas contribuiria de forma alarmante para os altos índices de analfabetismo que sempre marcaram a história da educação nacional. Assim, as escolas de classes multisseriadas, assumem uma importância social e política significativa nas áreas em que se situam, 
contribuindo no combate ao analfabetismo.

\section{CONCEITOS, PRINCÍPIOS E BASES LEGAIS SOBRE O PROJETO POLÍTICO PEDAGÓGICO}

Diante dos desafios que ora se apresentam no interior das escolas do campo, faz-se necessário um planejamento mais sistematizado de ações com o intuito de definir metas e métodos para alcançá-los. Assim, o Projeto Político Pedagógico (PPP) configura-se em um instrumento teórico-metodológico que possibilita a superação dos inúmeros desafios do cotidiano escolar que deve contar com a participação de toda a comunidade escolar e seu entorno.

O PPP é composto de uma proposta flexível, participativa e em constante aperfeiçoamento. Concretiza-se a partir de um espaço aberto ao diálogo proposto aos diversos segmentos existentes no interior e exterior do espaço escolar, proporcionando a interação dos sujeitos envolvidos neste processo: gestor, equipe pedagógica, professores, alunos, pais, funcionários e demais comunitários, em um processo de ensino compartilhado e em consonância com as reais necessidades da escola e a comunidade da qual faz parte.

O PPP sempre foi objeto de pesquisa de professores, pesquisadores e instituições de ensino nos níveis nacional, estadual e municipal, quase sempre com o objetivo de melhorar a qualidade do ensino. A escola deve expor sua visão, realização e avaliação de projetos educacionais, pois precisa organizar seu trabalho docente de acordo com as necessidades formativas dos alunos. Nessa perspectiva, é imprescindível que a escola do campo como um todo assuma suas próprias responsabilidades e não espere que a esfera administrativa superior tome essa iniciativa, mas que lhe dê as condições necessárias para a execução da ação. Portanto, é importante fortalecer a relação entre a escola e o sistema de ensino (VEIGA, 2008).

O caminho que se deseja a todos é o de oferecer a comunidade atendida na escola sempre o que há de "melhor", no que diz respeito à aquisição da aprendizagem, no sentido de levar o aluno para uma condição de vida digna na sociedade em que está inserido, acredita-se que assim, professores, gestores e o corpo técnico da escola deve abandonar a postura de meros reprodutores do conhecimento. Somente dessa forma, envolvendo a comunidade escolar no processo de mudança se conseguirá formar alunos para permanecer no campo ou para seguir outras escolhas, o que significa um grande desafio para os dias de hoje, nos quais notam-se que a família, assim como diversos segmentos da própria comunidade escolar se distanciam da responsabilidade de educar.

A elaboração deste estudo pauta-se principalmente no desejo de participação coletiva, de partilha de saberes, nos quais estão incluídos os saberes tradicionais, inclusive das escolas dos assentamentos, das escolas indígenas, das escolas quilombolas, dentre outras. De acordo com Pimenta (1995, p. 61), o Projeto Político Pedagógico é o trabalho de planejamento que requer a participação e a reflexão coletiva. Tal concepção permite uma leitura da escola não só como reprodutora das relações sociais, mas também, na produção e transformação dessa mesma sociedade.

A educação deve ser considerada como processo para o desenvolvimento humano integral, instrumento gerado das transformações sociais. É a base para a aquisição da autonomia, fonte de visão prospectiva, fator de progresso econômico, político e social. Para tanto, este processo deve desenvolver a criatividade, o espírito crítico, a capacidade de analisar e sintetizar, o autoconhecimento, a socialização, a autonomia e a responsabilidade. Destarte, é possível a formação de um homem com aptidões e atitudes para colocar-se a serviço do bem comum, possuir 
espírito solidário, sentir o gosto pelo saber, dispor-se a conhecer-se, a desenvolver a capacidade afetiva, possuir visão inovadora (MORAES, 2013).

Libâneo (2006) relata sobre a proposta de autonomia escolar preconizada pelas Diretrizes Educacionais e Lei Básica $\left(\mathrm{n}^{\circ}\right) .9 .394$ / 1996 e, enfatiza o objetivo de descentralização e democratização do ensino escolar e do poder de decisão organizacional. Por meio do PPP, a equipe escolar pode ser solidariamente responsável pelo sucesso dos alunos e seu investimento na cidadania fundamental, além de contribuir para o sucesso de toda a instituição. Portanto, segundo Veiga (2008), a construção do PPP está vinculada aos meios de formação humana para seguir um caminho participativo e sólido, visando construir escolas melhores para todos. A escola é uma organização dinâmica com significado social geral e seu PPP também precisa manter a vitalidade e a vitalidade para orientar o desenvolvimento da escola.

Estabelecer um PPP é uma tarefa que exige seriedade, pesquisa, reflexão, diálogo e participação. Como todos sabemos, as escolas enfrentam muitas dificuldades e, a construção coletiva também envolve atritos/conflitos, afinal cada um é único e traz sua própria história, mas as pessoas pensam que a maior conquista ocorre nas diferenças (FERRARI, 2011).

Nesse contexto, a Escola Estadual Professor João Florentino da Silva Neto, na cidade de Cáceres-MT oferece um modelo democrático de PPP, que é pensado segundo as necessidades da comunidade na qual está inserida, possuindo turmas de Ensino Fundamental e Médio, na modalidade EJA, além atende a turmas regulares, porém todas alocadas na Educação do Campo. Vejamos adiante alguns preceitos que podem auxiliar no diálogo para que outros tantos sejam discutidos, revistos e ampliados na educação do/no campo.

Entre outros, o PPP da escola sob análise, segue as orientações da Secretaria do Estado de Mato Grosso - SEDUC-MT que estabelece a inserção de três grandes marcos a cada unidade escolar, marco SITUACIONAL, CONCEITUAL e OPERATIVO. Resumidamente no SITUACIONAL a escola deve inserir, de uma forma geral, as características da unidade, contextualização histórica e econômica da unidade escolar, - diagnóstico de indicadores educacionais, diagnóstico da realidade escolar; no CONCEITUAL: concepções de: educação, educação do campo, currículo, diversidade cultural e inclusão, relações étnicoraciais, no marco OPERATIVO deve apresentar a proposta curricular, a prática pedagógica e a avaliação. qu

Portanto, é muito importante a participação da comunidade de todos os atores envolvidos nesse processo, observa-se que cada lugar possui suas caracteristicas que devem ser levadas em consideração, ademais aqui no estado de Mato Grosso, em nossas escolas, há uma marca diferente em cada escola do campo, pois cada uma delas tem suas especificidades inerentes a sua realidade local.

\section{O PPP DA ESCOLA ESTADUAL PROFESSOR JOÃO FLORENTINO DA SILVA NETO, NA CIDADE DE CÁCERES-MT}

O Projeto Político Pedagógico - PPP da Escola Estadual Professor João Florentino da Silva Neto tem início com o histórico da unidade escolar, uma breve biografia do seu patrono e o seu período de fundação. O que pode parecer de certa forma uma consideração superficial, mas se trata de associar o lugar, sua origem, o seu pertencimento e a evolução material de um memoria que tem início numa escola alugada e em pouco mais de 5 anos se transfere para uma construção própria mesmo que ainda carente de aparelhamento. Trata-se, portanto, de uma escola do campo, do Distrito de Caramujo, no município de Cáceres, no estado do Mato Grosso. Segundo o autor 
A partir dessas formas de considerar os contextos, desdobram-se conceituações relacionadas com as teorias pedagógicas críticas. $\mathrm{O}$ fenômeno da educação exige ser considerado em suas relações com o econômico, o social e o cultural. A compreensão da educação exige que se recuperem informações sobre a dinâmica social na qual se inclui e tem sentido; em outras palavras, é necessário compreender a dinâmica da sociedade onde os processos educativos se realizam e adquirem sentidos.(GAMBOA, 2018,p. 120).

A Escola Estadual Professor João Florentino da Silva Neto é uma instituição pública que tem como mantenedora a Secretaria de Estado de Educação - SEDUC-MT, oficialmente mantida pelo governo do Estado Mato Grosso, oferecendo a Educação Básica nas modalidades: Ensino Fundamental do $6^{\circ}$ ao $9^{\circ}$ Ano e o Ensino Médio Regular, EJA, atendendo nos três turnos: matutino, vespertino e noturno, tendo um público bem diversificado, vindo das várias localidades, tanto na sede como nas salas anexas (Sadia, Paiol, Limoeiro, Laranjeira, Vila Aparecida e Horizonte D’Oeste) todas pertencentes ao município de Cáceres-MT.

Enquanto instituição, a escola em questão tem como filosofia a formação de cidadãos críticos, participativos, conscientes de seus direitos, deveres e obrigações através da construção e da socialização dos saberes científico, cultural e tecnológico, levando em consideração a sua realidade local de escola do campo dando-lhe condições para que desenvolva suas potencialidades através de uma formação humanística. Nesse ínterim, a narrativa inicial avisa da essencialidade do seu PPP, que, uma vez citadas as conjeturas locais da escola, voltam:

Às atenções para a elaboração de um Projeto Político Pedagógico de Escola do
Campo, tendo bem claro a necessidade de se pensar uma organização escolar e
curricular que além de alterar conteúdos e métodos, promova mudanças radicais
nas práticas e relações pedagógicas de modo que estas se pautem nas reais
necessidades do homem do campo (PPP-EEJFN, 2020, p. 3).

Pensando numa organização escolar de conteúdo e metodologias que tragam percepções locais e despertar para um enfrentamento de igualdade, pensando na realidade dos que fazem parte da comunidade escolar, assim, a figura do nome da escola é de um eminete professor, de certo modo altruísta que emprestou o seu nome à "Escola Estadual Professor João Florentino Silva Neto" como forma de homenageá-lo, "in memorian, João Florentino Silva Neto que assumiu no decorrer de vários anos os cargos de professor e coordenador pedagógico da (única na época) Escola Municipal Santo Antônio do Caramujo" (PPP-EEJFN, 2020, p. 4).

Após a apresentação e a disposição que geograficamente a delimita na zona rural de Cuiabá, o PPP faz um levantamento sociodemográfico da comunidade presente na escola e enumera como segundo ponto importante, o item: Contexto Social e Perfil Socioeconômico da Comunidade Escolar. O Distrito não possui grandes investimentos e a iluminação é considerada o fator mais precário. De acordo com o documento:

A sociedade atual vem sendo palco de constantes e rápidas mudanças em todos os seus segmentos: políticos, sociais e econômicos. Todas essas mudanças apresentam-se como desafios para a escola que tenta cumprir sua função social de acompanhar esse processo, para garantir ao indivíduo conhecimentos suficientes para não ficar à margem de toda essa evolução. $O$ distrito de Caramujo, criado pela lei $\mathrm{N}^{\circ}$ 5.348, DE 06 DE SETEMBRO DE 1988 - D.O. 06.09.88., possui de acordo com o IBGE 2010 uma população urbana de 1.442 pessoas e 1.376 na zona rural, totalizando 2.818 pessoas. Sua população sobrevive basicamente das indústrias de cerâmicas, posto de combustível, 
pequenas lavouras, trabalho doméstico, pecuária, venda da produção de leite ou ainda como diaristas nas fazendas da região. Lembrando que escolas, posto de saúde, também empregam alguns habitantes do distrito. Há ainda os programas sociais de distribuição de renda. (PPP-EEJFN, 2020, p. 5).

O terceiro ponto a ser abordado é a Sistêmica da Unidade Escolar, que trata de questões como: relação escola-comunidade; acolhimento e procedimentos de atendimento às famílias/responsáveis; acolhimento e procedimentos de atendimento aos estudantes; entrada e saída dos estudantes; alimentação e higiene dos estudantes; procedimentos de matrícula; organização da hora-atividade, e; organização da formação continuada, ou seja, a preocupação de reger a questão normativa é importante e discutida entre os gestores, professores e técnicos além de se regerem segundo as indicações da Secretaria de Educação do Estado de Mato Grosso. Nesse sentido cabe destacar que:

O Projeto de formação continuada é elaborado com estratégias e objetivos voltados para a prática do cotidiano da sala de aula de acordo com as orientações curriculares, a BNCC e apoio do CEFAPRO-MT na formação continuada de professores e funcionários contribuindo para que os conhecimentos sejam compartilhados, melhorando a prática dos profissionais da unidade escolar, procurando manter o foco nas orientações curriculares para Educação Básica do Campo do Estado de Mato Grosso. (PPP-EEJFN, 2020, p. 7).

Dentro desse contexto, percebe-se que a Escola do Campo em estudo procura trazer uma visão completa em termos de aprender e compreender a educação, e entrelaçar questões políticas, sociais e econômicas. Buscando uma formação continuada aos educadores do campo que contemple um conhecimento dos saberes universais aliados com as experiências e o contexto da sua realidade.

É importante salientar que a formação continuada dos profissionais da escola assume um papel essencial na construção de diálogos que possibilite perceber algumas soluções dos problemas encontrados na educação do campo. Pois

A formação continuada é uma exigência para os tempos atuais. Desse modo, pode-se afirmar que a formação docente acontece em continuum, iniciada com a escolarização básica, que depois se complementa nos cursos de formação inicial, com instrumentalização do professor para agir na prática social, para atuar no mundo e no mercado de trabalho. (ROMANOWSKI, 2007, p.138),

Para tanto, a formação continuada na escola é considerada como um momento para a reflexão das ações, pois a educação no campo, aliada a estes saberes do campo devem ser pensadas como uma ferramenta educacional, em prol a valorização do desenvolvimento na prática, pois, assim estariam aprendendo na teoria e na prática conceitos que mesmo os básicos auxiliam na vida diária do sujeito. Nesse sentido,

Torna-se necessário um educador que tenha compromisso, condições teóricas e práticas para desconstruir as práticas e ideias que forjaram o meio e a escola rural. [...] as necessidades presentes na escola do campo exigem um profissional com uma formação bem mais ampliada e abrangente, capaz de compreender uma série de dimensões educativas e deformativas presentes na tensa realidade do campo na atualidade. Para tanto, precisa de uma formação que o habilite a compreender a gravidade e a complexidade dos novos processos de acumulação de capital no campo, que têm interferência direta sobre a realidade do território rural; sobre os 
destinos da infância e juventude do campo que ele irá educar e sobre o próprio destino e permanência das escolas do campo (MOLINA; ANTUNES-ROCHA, 2014, p.226).

Dessa forma, a formação do educador do campo deve levar esse sujeito a compreender o seu meio, rever sua posição sobre a educação e o currículo, além de suas concepções de educação. De acordo com Arroyo (2011), o professor da Educação Básica do Campo não deve ser apenas um transmissor ou repassador de conhecimento e sim, ir além dos conteúdos aplicados em sala de aula. Pois, é visto que, o ensino no campo adquiri a importância de aproximação entre docentes e discentes que lhe possibilita a realização de um trabalho contextualizado visando o maior conhecimento do estudante, de modo a compreender suas dificuldades e seus tempos de aprendizagem.

Por este motivo que o currículo pode e deve ser adaptado a partir da realidade e especificidade de cada unidade escolar, existe uma Base Nacional Comum Curricular que não pode ser ignorada, da mesma forma que um currículo específico que a Escola Estadual Joao Florentino da Silva Neto em seu PPP chama de Parte diversificada que contempla os saberes e conhecimentos dos povos do campo, estes saberes precisam se conversar no espaço escolar e o trabalho multi/interdisciplinar é importante neste sentido.

O quarto item a ser apresentado é o Diagnóstico de Indicadores Educacionais, no qual apresenta-se os resultados e a análise de proficiência, evasão, matrícula, fluxo, distorção idade/ano SAEB nacional e a avaliação estadual. Esse acerto, é merecedor de um olhar bem específico, uma vez que os resultados dependem de uma leitura mais ampla e contextualizada de acordo com os parâmetros nacionais e estaduais. Após a discussão quantitativa, assinalam o reconhecimento de que "houve um rendimento satisfatório em 2017 em relação aos anos anteriores" (PPP-EEJFN, 2020, p. 9).

A partir do ponto cinco, é realizado o diagnóstico da realidade escolar, apresentado em sete dimensões e cada dimensão com as suas pertinências. Não mais importante que as abordagens anteriores, essa narrativa se constitui no olhar mais sensível acerca dos problemas pertinentes, bem como, das soluções possíveis que são apontadas. Embora, pelo exposto, a discussão se volte para a compreensão das dinâmicas e contextos nos quais se dão as relações interpessoais, de trabalho, pedagógicas etc. Assim, são abordadas as dimensões e as suas subdivisões, dispostas no quadro abaixo, com as suas respectivas subdivisões.

Quadro 1 - As dimensões do PPP e do que tratam as suas avaliações

\begin{tabular}{|l|l|}
\hline \multicolumn{1}{|c|}{ DIMENSÕES } & \multicolumn{1}{c|}{ TRATAM DE } \\
\hline I - Ambiente educativo & • Análise do Relacionamento Interpessoal e Atendimento a Diversidade \\
& - Análise das normas de Convivência \\
\hline II - Prática Pedagógica & - Análise do Trabalho com a Diversidade \\
& - Análise do Relacionamento Interpessoal e Atendimento a Diversidade \\
& - Análise da Proposta Pedagógica, do Planejamento Escolar e dos Recursos de \\
& - Ensino-Aprendizagem Utilizados \\
& - Análise do Incentivo à Autonomia e ao Trabalho Coletivo \\
\hline III - Avaliação & - Análise da Prática Pedagógica Inclusiva Monitoramento do Processo de Aprendizagem dos Alunos - Diário \\
& - Análise dos Mecanismos de Avaliação dos Alunos \\
& - Análise dos Acesso e Compreensão dos Indicadores Oficiais de Avaliação \\
& - Análise da Avaliação do Trabalho dos Profissionais da Escola \\
\hline
\end{tabular}


DOI: $10.12957 /$ teias.2021.59095

\begin{tabular}{|c|c|}
\hline $\begin{array}{l}\text { IV- Gestão Escolar } \\
\text { Democrática }\end{array}$ & $\begin{array}{l}\text { - Análise da Democratização das Informações } \\
\text { - Análise da Participação da Comunidade Escolar } \\
\text { - Análise da Interação com os Órgãos Oficiais e Parceiros } \\
\text { - Análise do Tratamento aos Conflitos na Escola }\end{array}$ \\
\hline $\begin{array}{l}\text { V- Formação e Condições de } \\
\text { Trabalho dos Profissionais da } \\
\text { Escola }\end{array}$ & $\begin{array}{l}\text { - Análise da Formação Continuada } \\
\text { - Análise da Suficiência da Equipe Escolar } \\
\text { - Análise da Assiduidade e da Estabilidade da Equipe Escolar }\end{array}$ \\
\hline VI - Ambiente Físico Escolar & $\begin{array}{l}\text { - Análise dos Recursos Físicos, Materiais e Pedagógicos Levando em } \\
\text { Consideração a Suficiência, a Qualidade e o Aproveitamento }\end{array}$ \\
\hline $\begin{array}{l}\text { VII- Acesso, Permanência e } \\
\text { Sucesso na Escola }\end{array}$ & $\begin{array}{l}\text { - Análise do Fluxo (frequência, retenção e evasão escolar dos alunos) } \\
\text { - Análise da Atenção Dedicada aos Alunos com Defasagem de Aprendizagem } \\
\text { - Análise do Acesso e Compreensão dos Indicadores Oficiais de Avaliação } \\
\text { (Interno e Externo) }\end{array}$ \\
\hline
\end{tabular}

Fonte: (PPP-EEJFN, 2020).

Evidenciar os pontos abordados nas diferentes dimensões nos leva a ter a ideia geral do que trata um PPP, a sua preocupação com as questões mais relevantes, no sentido de que realizase análise de dados atualizados, presentes, apontados durante o ano letivo vigente e assim, conseguem traçar um diagnóstico mais aproximado da escola e do seu entorno. Em se tratando de uma escola que possui ensino regular e EJA, nessa segunda modalidade a classe multisseriadas ainda é uma preocupação.

Mas, explicitamente o PPP da Escola Estadual Professor João Florentino da Silva Neto aponta as necessidades de melhoria, sem desconsiderar seus avanços. Por exemplo, diante dos parâmetros estaduais e nacionais, a epidemia de Covid-19 aflorou questões de um ano letivo atípico, que evidenciou a carência de transporte com segurança, serviços de internet, falta de acesso pela comunidade à internet, falta de uma plataforma adequada para a realidade e as demais questões que podem ser encontradas em boa parte das escolas do campo.

Por fim, os autores traçam o marco teórico dando enfase a autores cuja trajetórias teóricas estão de acordo com uma educação popular, sensível à luta da população do campo. O que é pertinente atentar, uma vez que, esse marco teórico firma a filosofia da escola e refirma aquilo que o seu complexo conjunto e entorno consideram como a educação que pretendem para uma escola do/no campo.

\section{CONSIDERAÇÕES FINAIS}

O cumprimento desta pesquisa objetivou analisar os reflexos e contribuições do Projeto Político Pedagógico na Educação do Campo da Escola Estadual Professor João Florentino da Silva Neto, com vista a diagnosticar a valorização da identidade dos alunos enquanto sujeitos do campo e sua relação com a concepção de Educação do campo. Diante dessas evidencias, conclui-se que o PPP é um planemamento para a Educação do/no Campo, voltado para a articulação da comunidade escolar, porém é preciso que a articulação para que tudo aconteça possa favorecer uma organização, cujo clima seja compromisso de todos os atores do contexto educativo.

Desse modo, entendemos que a Educação para as escolas do campo deva ser pensada também a partir dos processos sociais que se inserem no campo, devendo com isso considerar a política agrícola, a política de saúde e a política de educação, estas voltadas as suas especificidades 
e principalmente levar em consideração os conhecimentos presentes na comunidade, constituindo ponto de partida, o Projeto Político Pedagógico. Portanto, o PPP precisa ser pensado e elaborado pelos gestores, juntamente com todos profissionais da educação e a comunidade escolar, assim a participação de todos os atores é muito importante para abertura da escola, para além de seus muros, onde provavelmente existem muitos problemas a serem enfrentados.

Destarte, a formação do educador do campo deve levar o sujeito a compreender o seu meio, rever sua posição sobre a educação e o currículo, além de suas concepções de educação. De acordo com Arroyo (2011), o professor da Educação Básica do Campo não deve ser apenas um transmissor ou repassador de conhecimento e sim, ir além dos conteúdos aplicados em sala de aula. Pois, é visto que, o ensino no campo adquiri a importância de aproximação entre docentes e discentes que lhe possibilita a realização de um trabalho contextualizado visando o maior conhecimento do estudante, de modo a compreender suas dificuldades e seus tempos de aprendizagem.

No caso da escola supracitada, longe de considerarmos um modelo perfeito, mas caminha para o ideal. Vai no sentido daquilo que acreditamos ser um caminho a ser construído cotidianamente e, que corrobora com o fortalecimento de uma Educação do Campo de qualidade, compatível com os preceitos de equidade, empatia e alteridade.

\section{REFERÊNCIAS}

AMIN, Samir; HOUTART, François (Orgs.). Mundialização das resistências. São Paulo: Cortez, 2003. ARROYO, Miguel González. Currículo, território em disputa. Petrópolis, RJ: Vozes, 2011.

ARROYO, Miguel González; CALDART, Roseli Salete; MOLINA, Mônica Castagna. (ORGs). Por uma Educação do Campo. Petrópolis, RJ: Vozes, 2004.

ANTUNES-ROCHA, Maria Isabel; HAGE, Salomão Mufarrej. Escola de Direito: ressignificando a escola multisseriada. Belo Horizonte: Autêntica, 2010.

BARROS, Oscar Ferreira. Classes Multisseriadas em Escola Rural-Ribeirinha: a práxis pedagógica de uma educadora. In: OLIVEIRA, Ivanilde Apoluceno de (Org.). Caderno de Atividades Pedagógicas em Educaşão Popular. Nº 1, Belém: CCSE- UEPA, 2007.

BOFF, Leonardo. Eciesiogênese: a reinvenção da igreja. Rio de Janeiro: Record, 2008.

BRANDÃO, Carlos Rodrigues. Educação Popular. 2a .ed. São Paulo: Brasiliense, 1986.

CALDART, Roseli Salete. Elementos para a construção do Projeto Politico e Pedagógico da Educaşão do Campo. In: PARANÁ. Secretaria de Estado da Educação. Cadernos Temáticos: educação do campo, Curitiba: SEED-PR, 2005.

CARMONA, Raquel Miranda.; LUNA, Emanuel Paulino. Apontamentos sobre o capital fundiário e a propriedade privada da terra n’Os limites do capital de David Harvey. Revista Campo do Saber, v. 1, 2019.

FERRARI, Greicimara Vogti. A importância do coletivo na construção do projeto político pedagógico da instituição escolar. In: Perspectiva. 35(132): 159-170. 2011.

FREIRE, Paulo. Educação como prática de liberdade. 12 ed. Rio de Janeiro: Ed. Paz e Terra, 1981.

FREIRE, Paulo. Pedagogia da esperança. Rio de Janeiro: Paz e Terra, 1992.

FREIRE, Paulo. Pedagogia da esperança: um reencontro com a pedagogia do oprimido. Rio de Janeiro, 1992. $8^{a}$ edição. Editora Paz e Terra.

GAMBOA, Silvio Sánchez. Pesquisa em educação: métodos e epistemologias. $3^{\mathrm{a}}$ ed. Chapecó, SC: Argos, 2018. 
HAGE, Salomão. A realidade das escolas multisseriadas frente às conquistas na legislação nacional. In: Anais da 29a reunião anual da ANPED. Caxambu - MG, 2006.

LEITE, Sérgio Celani. Escola rural: urbanização e políticas educacionais. 2. ed. São Paulo: Cortez, 1999. LIBÂNEO, José Carlos. Organização e gestão da Escola: teoria e prática. 5. ed. Goiânia: Alternativa, 2006.

MACHADO, Ilma Ferreira.; VENDRAMINI, Celia Regina. Políticas públicas para a educação do campo: da necessidade aos limites. Revista Ibero-Americana de Estudos em Educação. v. 8, n. 1, p. 1-16, 2013. MENEZES, Ebenezer Takano de; SANTOS, Thais Helena dos. "Classes multisseriadas" (verbete). Dicionário Interativo da Educação Brasileira - EducaBrasil. São Paulo: Midiamix Editora. (2002) Disponível em: http://www.educabrasil.com.br. Acesso em 09 de novembro de 2020.

MOLINA, Mônica Castagna;; ANTUNES-ROCHA, Maria Isabel. Educação do campo: história, práticas e desafios no âmbito das políticas de formação de educadores - reflexões sobre o Pronera e o Procampo. Revista Reflexão e Ação, v.22, n.2, p.220-253, jul./dez.2014.

MORAES, Elis Regina de Freitas. Projeto Politico Pedagógico. Aracajú: Colégio Purificação, 2013.

MUNARIM, Antônio. Elementos para uma política pública de Educação do Campo. In: MOLINA, Mônica Castagna (Org.). Educação do Campo e Pesquisa: questões para reflexão. Brasília: Ministério do Desenvolvimento Agrário, 2006.

PAIVA, Vanilda. Educaşão Popular e educação de adultos. São Paulo: Loyola, 1987.

PIMENTA, Selma Garrido Oliveira. Estágio na Formação dos Professores: Unidade entre Teoria e Prática? In: Cadernos de Pesquisas. 94: 58-73. São Paulo, 1995.

PPP - Projeto Politico Pedagógico da Escola Estadual João Florentino da Silva Neto -EEJFN, 2020.

PIZA, Fernando Ferreira; SENA, Lilian Barbosa, PMG 3 Escola Ativa. Salto para o Futuro. Disponível em www.tvebrasil.com.br/saltoparaofuturo/boletim 2001. Consulta em 23/03/2021

ROMANOWSKI, Joana Paulin. Formação e Profissionalização docente. Curitiba: Ibpex, 2007.

SANDRONI, Paulo. Novíssimo Dicionário de Economia, São Paulo: Best Seller, 1999.

SILVA, André Luiz Batista da. A educação do campo no contexto da luta do movimento social: uma análise bistórica das lutas, conquistas e resistências a partir do Movimento Nacional da Educação do Campo. Rev. Bras. Hist. Educ., Maringá, v. 20, e112, 2020.

VEIGA, Ilma Passos Alencastro (Org.). Projeto Político Pedagógico da escola: uma construção possivvel. $24^{\circ}$ ed. São Paulo: Papirus, 2008.

Submetido em mês de abril 2021

Aprovado em outubro de 2021

\section{Informações do(a)(s) autor(a)(es)}

Leandro de Almeida

Programa de Pós-graduação em Educação e Novas Tecnologias (PPGENT), Centro Universitário Internacional (UNINTER)

E-mail.leandro.a@unemat.br

ORCID: https://orcid.org/0000-0002-8938-4180

Link Lattes. http:/ / lattes.cnpq.br/3281542444402292 
Joana Paulin Romanoswski

Programa de Pós-graduação em Educação e Novas Tecnologias (PPGENT), Centro Universitário Internacional (UNINTER)

E-mail. joana.romanowski@gmail.com

ORCID: https://orcid.org/0000-0001-7043-5534

Link Lattes. http://lattes.cnpq.br/7752218478865716 